\title{
Relation between proteinuria and acute kidney injury in patients with severe burns
}

Jiong Yu Hu${ }^{1 \dagger}$, Xin Chun Meng ${ }^{2 \dagger}$, Jian $\mathrm{Han}^{3}$, Fei Xiang ${ }^{1}$, Ya Dong Fang ${ }^{1}$, Jun Wu', Yi Zhi Peng ${ }^{1}$, Ya Zhou Wu ${ }^{4}$, Yue Sheng Huang ${ }^{1}$ and Qi Zhi Luo ${ }^{1 *}$

\begin{abstract}
Introduction: Proteinuria in burn patients is common, and may be associated with acute kidney injury (AKI) and adverse outcomes. We evaluated the incidences, outcomes, characteristics and determinants of proteinuria and its influence on AKI and outcomes in burn patients.
\end{abstract}

Methods: This retrospective study was carried out in a hospital's burn department. The study population consisted of patients with burn injuries admitted during a five-year period. Positive urine dipstick readings were defined as mild $( \pm$ or $1+)$ or heavy $(\geq 2+)$ proteinuria, and AKI was diagnosed and staged according to the Risk, Injury, Failure, Loss, End Stage (RIFLE) classification system. Patient characteristics, management and outcomes were evaluated for associations with proteinuria using nonparametric tests, chi-square $\left(\chi^{2}\right)$ tests and binary logistic regression.

Results: Of the patients admitted to the burn unit during the study period ( $n=2,497), 865$ (34.64\%) were classified as having proteinuria. In the patients whose total burn surface areas (TBSA) were $>30 \%(n=396), 271$ patients (68.43\%) had proteinuria and 152 of these patients (56.09\%) met AKI criteria. No patients without proteinuria developed AKI. Intensive care unit (ICU) mortality rates were $0.8 \%, 16.67 \%$ and $30.77 \%(P<0.001)$ in the groups with no, mild and heavy proteinuria, respectively. Logistic regression analysis identified proteinuria (OR 4.48; $95 \% \mathrm{Cl}$, 2.824 to $7.108 ; P<0.001)$ and sequential organ failure assessment ( $\mathrm{OR} 1.383 ; 95 \% \mathrm{Cl}, 1.267$ to $1.509 ; P<0.001)$ as risk factors for AKI.

Conclusions: We observed a high prevalence of proteinuria in patients with severe burns (> 30\% TBSA). Severely burned patients with proteinuria had a high risk of developing AKI and a poor prognosis for survival. This suggests that proteinuria should be used for identifying burn patients at risk of developing AKI.

Keywords: Severe burn, Proteinuria, Acute kidney injury, Risk factors, Mortality

\section{Introduction}

Acute kidney injury (AKI) is increasingly common and is associated with adverse short- and long-term outcomes in various clinical settings [1], including patients with severe burns [2]. In the acute phase, as kidney function declines, AKI is associated with excess mortality [3,4], maximum Sequential Organ Failure Assessment (SOFA) and extended intensive care unit (ICU) stays $[2,5,6]$. Although kidney function recovers for most burn patients survivors [7-10], some survivors have persistent loss of kidney

\footnotetext{
* Correspondence: augustus100@sina.com

+ Contributed equally

'Institute of Burn Research, Southwest Hospital, State Key Laboratory of Trauma, Burns and Combined Injury, Chongqing Key Lab for Disease

Proteomics, Third Military Medical University, Chongqing 400038, PR China

Full list of author information is available at the end of the article
}

function and require long-term dialysis [11]. The key strategy for prevention of AKI is to identify those at highest risk so that prophylactic measures can be administered.

As defined by the RIFLE (Risk, Injury, Failure, Loss, End Stage) classification system, the diagnosis of AKI is currently based on changes in the serum creatinine $(\mathrm{sCr})$ or urine output $[12,13]$. However, these parameters often lag behind acute changes in renal function and, therefore, underestimate the degree of renal dysfunction in acute care settings [14]. Recent improvements in understanding AKI have resulted in the implementation of proteinuria [13,15-17] and some novel biomarkers [18-20] as means of more accurately assessing for AKI.

Proteinuria is an indicator of both glomerular and renal endothelial injury in chronic disease [21,22], acute illness
Ciomed Central

() 2012 Hu et al.; licensee BioMed Central Ltd. This is an open access article distributed under the terms of the Creative Commons Attribution License (http://creativecommons.org/licenses/by/2.0), which permits unrestricted use, distribution, and reproduction in any medium, provided the original work is properly cited. 
or is due to surgery [23-26]. Glomerular proteinuria is a feature of chronic kidney disease (CKD) and intrinsic renal disease, whereas tubular proteinuria occurs more frequently in AKI. Dipstick urinalysis is a cheap and convenient means of diagnosing proteinuria, and it is a routine test for in-patients in our burn center (the Burn Department of Southwest Hospital). Proteinuria is commonly observed in patients with severe burns $[27,28]$, but the usefulness of proteinuria for predicting the risk of AKI and prognosis has not been documented for burn patients. In this study, we examined associations between proteinuria and adverse clinical outcomes, including mortality and AKI incidence in burn patients. We hypothesized that burn patients with proteinuria would be at higher risk of AKI and adverse outcomes than patients without proteinuria.

\section{Materials and methods}

This retrospective study was conducted over a five-year period (October 2006 to September 2010) in a 200-bed specialized burn department. All patients with burn injuries admitted to the Burn Department of Southwest Hospital were included in the study. This study was approved by the Human Subjects Review Board of The Third Military Medical University, and did not require informed consent because it was a study of routinely collected clinical data. All relevant information was provided following the STROBE (STrengthening the Reporting of OBservational studies in Epidemiology) Guideline.

Exclusion criteria for the study were: age $<18$ years or $>75$ years; non-burn diagnosis (reconstructive surgery); non-survivable burns (decision for comfort care on admission); pregnancy; admission for less than $72 \mathrm{~h}$; previous dialysis; previous abnormal renal function with $\mathrm{sCr}>133$ $\mu \mathrm{mol} / \mathrm{L}$; or diagnosed with diabetes or hypertension.

Patient resuscitation in the first $48 \mathrm{~h}$ was based on the Third Military Medical University formula [29] (see Additional file 1). Thereafter, maintenance crystalloid infusion rates were calculated using standard formulas for insensible wound fluid losses. Urine volumes $>0.5 \mathrm{ml} / \mathrm{Kg} \cdot \mathrm{h}^{-1}$ in the first $48 \mathrm{~h}$ post injury were considered to be indicative of effective resuscitation. Enteral or intravenous nutrition was provided after the first $48 \mathrm{~h}$ post-injury for patients with total burn surface areas (TBSA) $>50 \%$, and prophylactic antibiotics were used for patients with TBSA > 30\%. Demographic and clinical data were recorded for each patient, including proteinuria; sCr; TBSA and depth; comorbidities; escharotomies; inhalation, chemical, or electrical injuries; mechanical ventilation; continuous renal replacement therapy (CRRT); abdominal compartment syndrome (ACS); nephrotoxic drugs (vancomycin, amphotericin $\mathrm{B}$, polymyxin $\mathrm{E}$, aminoglycosides); vasopressors (dopamine, epinephrine, norepinephrine); administration of colloidal solutions for resuscitation; urine volume in the first $48 \mathrm{~h}$ post injury; ICU length of stay; and mortality. Intra-abdominal pressure (IAP) was measured using once daily urinary bladder pressure measurements, and ACS was defined as a sustained IAP $>20 \mathrm{~mm} \mathrm{Hg}$ that was associated with development of organ dysfunction/failure [30]. Proteinuria was determined with urine dipsticks using an automated urine analyzer (H800, Dirui, Changchun, China), and defined as normal (negative), mild ( \pm or $1+$, approximately $>5$ to $20 \mathrm{mg} / \mathrm{dL}$ ), or heavy ( $\geq 2+$, approximately $\geq 100 \mathrm{mg} / \mathrm{dL}$ ). The maximal level of proteinuria prior to the first diagnosis of AKI was recorded in AKI patients and the maximum level at any time in non-AKI patients. Urine protein results were recorded by the laboratory examiner, and the urine analyzer was calibrated by the factory engineer every two weeks to ensure accuracy and precision.

Baseline $\mathrm{sCr}$ values were measured within three months prior to admission. For the patients without a $\mathrm{sCr}$ test within three months, the first $\mathrm{sCr}$ value after admission was adopted as the baseline $\mathrm{sCr}$ values if the first $\mathrm{sCr}$ value was normal $(<106 \mu \mathrm{M}$ for male, and $<88 \mu \mathrm{M}$ for female). If the first $\mathrm{sCr}$ value was abnormal, patients were assigned to a baseline eGFR of $75 \mathrm{ml} / \mathrm{min} / 1.73 \mathrm{~m}^{2}$, and the Modification of Diet in Renal Disease (MDRD) equation was applied [12,31]. The RIFLE class was determined according to the worst degree of either $\mathrm{sCr}$ or urine output criteria [12]. Systemic inflammatory response syndrome (SIRS) and sepsis were diagnosed according to criteria defined by the American College of Chest Physicians and the Society of Critical Care Medicine [32]. For the diagnosis of multiple organ dysfunction or failure, Sequential Organ Failure Assessment (SOFA) Scores were computed daily and the maximum was used for this study [33].

\section{Statistical analysis}

Continuous variables were expressed as medians and quartile ranges. Dichotomous and categorical variables were expressed as proportions and compared using nonparametric and chi-square $\left(\chi^{2}\right)$ tests. Comparisons of location parameters for continuous data were analyzed with Mann-Whitney U and Kruskal-Wallis H tests. Risk factors were assessed using a binary logistic regression with proteinuria, AKI and ICU mortality as the dependent outcome variables. In all comparisons, a $P$-value of $<0.05$ was considered statistically significant. Statistical analyses were performed with the software program IBM SPSS STATISTIC, version 19 (SPSS Inc, Chicago, IL, USA).

\section{Results}

A total of 3,224 patients were admitted to the Burn Department during the study period, and 2,497 patients 
met the study's inclusion criteria (Figure 1). Patients were excluded on the basis of non-burn diagnoses $(n=$ $346)$; age $<18$ years or $>75$ years $(n=237)$; abnormal renal function preoperatively (defined as $\mathrm{sCr}>133$ $\mu \mathrm{mol} / \mathrm{L})$ or previous dialysis $(n=12)$; patients who stayed less than 72 hours after admission $(n=72)$; patients who elected comfort care upon admission $(n=$ $32)$; and pregnancy $(n=28)$.

All patients had their first measurement of proteinuria and $\mathrm{sCr}$ around $2 \mathrm{~h}$ after admission. Maximum proteinuria values of the remaining 2,497 patients and maximum $\mathrm{sCr}$ values of the 396 patients, whose TBSA > 30\%, were recorded, in which maximum proteinuria was defined as the maximum value before AKI incidence for patients with AKI. Patient proteinuria and TBSA values were summarized (Table 1). In the remaining 2,497 patients, 865
(34.64\%) developed proteinuria, and the patients with larger TBSA were more likely to have proteinuria $(P<0.001)$.

The difference between the first and maximum proteinuria has been summarized in Figure 2. Of the patients with TBSA > 30\% $(n=396), 271$ patients had proteinuria, in which 211 had proteinuria at their first measurement. A total of 151 patients developed AKI, 43 of which had AKI on admission. It should be specially noted that none of the patients without proteinuria had AKI, which means that the continued absence of proteinuria excludes the development of AKI.

Patient categories were compared based on proteinuria (Table 2). Of the patients with TBSA $>30 \%(n=396), 180$ (45.45\%) had mild and 91 (22.98\%) had heavy proteinuria. Of the patients with proteinuria $(n=271), 151(55.72 \%)$ had AKI, with RIFLE classifications of: Risk $(n=83$;

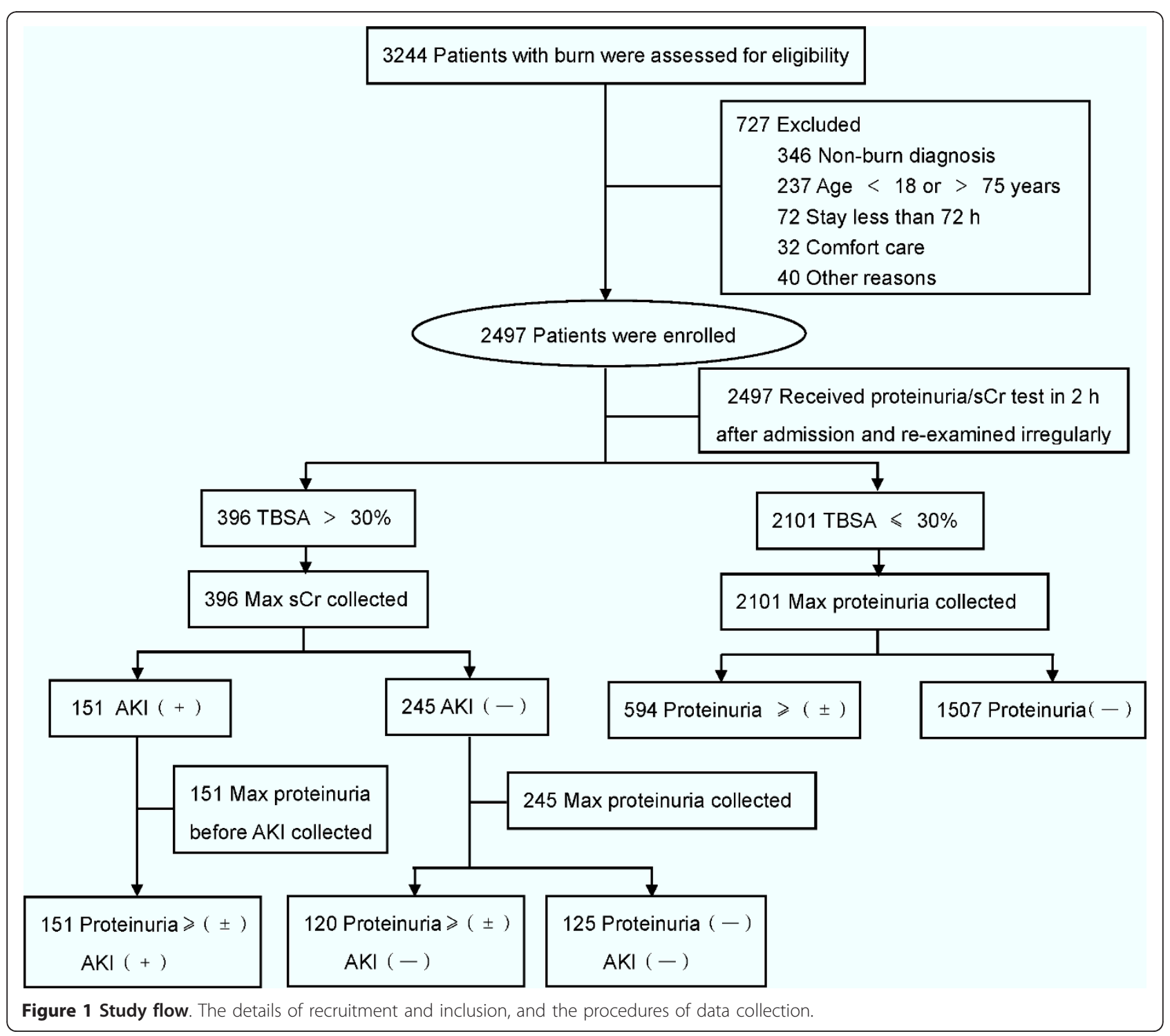


Table 1 Comparison of TBSA with proteinuria $(n=2,497)$

\begin{tabular}{llll}
\hline TBSA (\%) & $\begin{array}{l}\text { No proteinuria } \\
(\boldsymbol{n}=\mathbf{1 , 6 3 2 )}\end{array}$ & $\begin{array}{l}\text { Proteinuria } \\
(\boldsymbol{n}=\mathbf{8 6 5})\end{array}$ & $\begin{array}{l}\text { Proteinuria } \\
(\mathbf{\%})\end{array}$ \\
\hline$\leq 10$ & 973 & 324 & 24.98 \\
11 to 30 & 533 & 270 & 33.62 \\
31 to 50 & 99 & 110 & 52.63 \\
51 to 70 & 16 & 67 & 80.72 \\
$>70$ & 11 & 94 & 89.52 \\
\hline
\end{tabular}

TBSA, total burn surface area

54.97\%); Injury ( $n=52 ; 34.44 \%)$; and Failure $(n=16$; $10.60 \%)$. Non-parametric tests (univariate analysis) showed significant differences among the groups for: age, TBSA, ACS, escharotomy, comorbidities, nephrotoxic drugs, inhalation injury, urine output at the shock stage, vasopressor in first $48 \mathrm{~h}$, sepsis during the ICU stay, positive blood culture, maximum SOFA and RIFLE $(P<0.05)$. Patients with proteinuria were prone to having CRRT $(P=$ $0.013)$, longer mechanical ventilation duration $(P<0.001)$, longer ICU stays $(P<0.001)$, and higher mortality rates $(0.8 \%, 16.67 \%$ and $30.77 \%$ for none, mild and heavy proteinuria) $(P<0.001)$.

The characteristics and outcomes of patients with proteinuria according to AKI were summarized (Table 3). Among the 396 patients with TBSA > 30\%, 357 had baseline $\mathrm{sCr}$ values, whereas the remaining 41 used eGFR derived values. When diagnosing the AKI, 102 achieved RIFLE maximum by $\mathrm{sCr}$ criteria, 19 by urine criteria and 31 by both criteria. The patients with AKI had higher TBSA, ACS, escharotomy, proteinuria, sepsis during ICU stay and maximum SOFA values compared to the patients without AKI $(P<0.05)$. Patients with AKI were prone to have CRRT $(P=0.002)$, longer mechanical ventilation durations $(P<0.001)$, and extended ICU stays $(P<0.001)$.
Mortality rates of patients with and without AKI were $12.50 \%$ and $28.48 \%(P=0.001)$, respectively.

Logistic regression analysis identified TBSA (OR 1.038; 95\% CI, 1.022 to $1.054 ; P<0.001$ ), sepsis (OR 1.052; 95\% CI, 1.539 to 5.331; $P=0.001$ ), and age (OR 1.026; 95\% CI, 1.007 to $1.046 ; P=0.006)$ as independent risk factors for proteinuria (Table 4); SOFA (OR 1.383; 95\% CI, 1.267 to $1.509 ; P<0.001)$ and proteinuria (OR 4.480; 95\% CI, 2.824 to $7.108 ; P<0.001)$ as independent risk factors for AKI (Table 5); age (OR 1.085; 95\% CI, 1.048 to $1.123 ; P<0.001$ ), TBSA (OR $1.053 ; 95 \% \mathrm{CI}, 1.032$ to 1.075; $P<0.001$ ), proteinuria (OR 1.932; 95\% CI, 1.000 to $3.734 ; P=0.050$ ), associated injury (OR 2.446; $95 \%$ CI, 3.986 to $33.440 ; P<0.001$ ) and RIFLE (OR 2.289; 95\% CI, 1.577 to $3.322 ; P<0.001)$ as independent risk factors for ICU mortality (Table 6).

\section{Discussion}

In this hospital-based study, we found that proteinuria was common $(68.26 \%$ ) in severe burn patients (> 30\% TBSA), and proteinuria should be used to identify severe burn patients at risk of AKI, as well as for prognosis and identification of burn patients needing intensive care.

Acute kidney injury is characterized as a rapid loss of kidney function which clinically manifests as an abrupt and sustained rise in urea and creatinine. Life threatening consequences of AKI include volume overload, metabolic acidosis, hyperkalaemia and effects on other organ systems [34]. AKI is associated with increased morbidity, mortality and hospitalization costs [19]. So it is significantly meaningful to identify the patients at risk of AKI and take appropriate treatments. However, decreased creatinine production and hemodilution will significantly blunt increases in creatinine that could be indices of AKI in

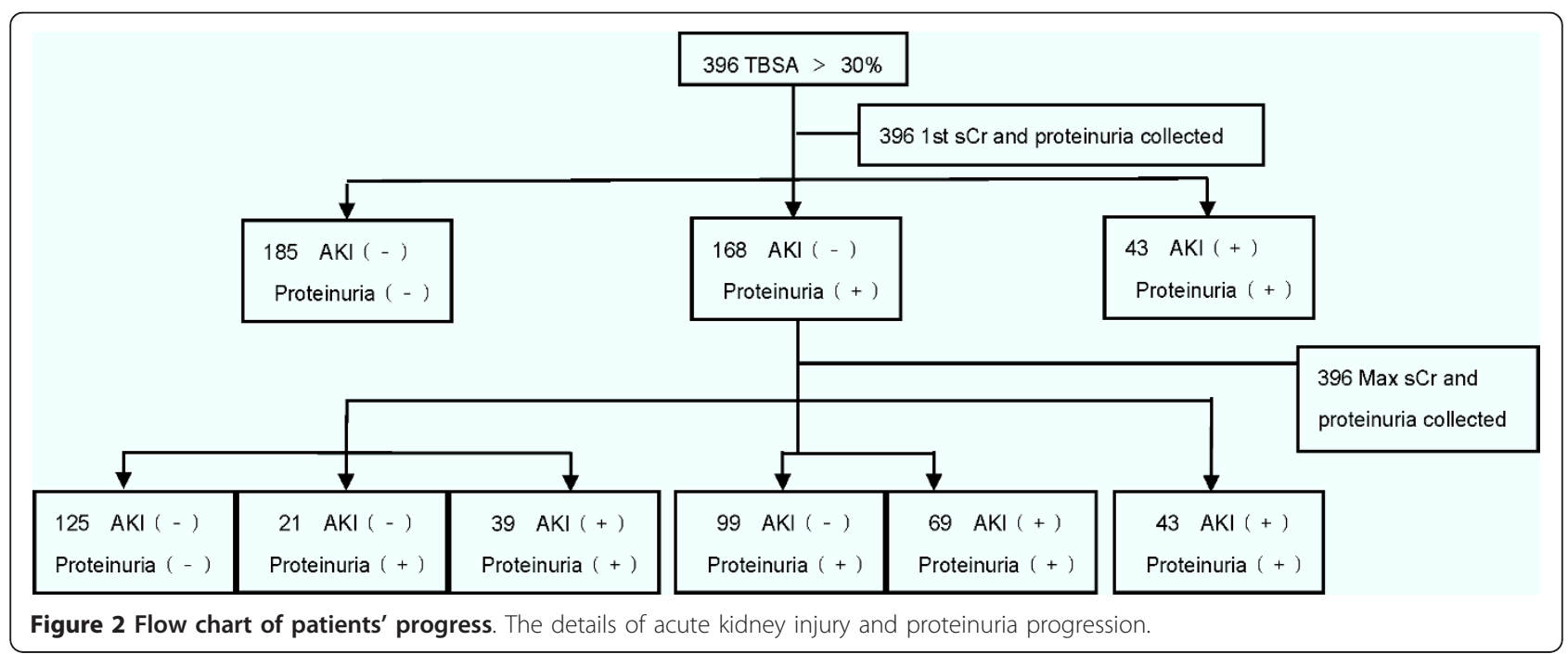


Table 2 Characteristics and outcomes of patients according to degree of proteinuria $(n=396)$

\begin{tabular}{|c|c|c|c|c|}
\hline & $\begin{array}{l}\text { None } \\
(n=125)\end{array}$ & $\begin{array}{l}\text { Mild } \\
(n=180)\end{array}$ & $\begin{array}{l}\text { Heavy } \\
(n=91)\end{array}$ & $P$-value \\
\hline Age (years) & $38(16.00)$ & $42(16.75)$ & $41(15.00)$ & 0.050 \\
\hline Gender (\% of males) & 72.80 & 83.89 & 86.81 & 0.150 \\
\hline TBSA (\%) & $38(15.50)$ & $54.4(35.00)$ & $70(41.00)$ & $<0.001$ \\
\hline dTBSA (\%) & $35(13.50)$ & $48(33.00)$ & $60(39.00)$ & $<0.001$ \\
\hline Escharotomy (\%) & $3(15.50)$ & $9(27.75)$ & $24(38.00)$ & $<0.001$ \\
\hline Electrical injury (\%) & 7.20 & 7.22 & 10.99 & 0.511 \\
\hline Chemical injury (\%) & 24.00 & 17.88 & 10.99 & 0.049 \\
\hline Inhalation injury (\%) & 25.60 & 46.67 & 48.35 & $<0.001$ \\
\hline Comorbidities (\%) & 1.60 & 9.44 & 7.69 & 0.042 \\
\hline ACS (\%) & 3.20 & 17.78 & 25.78 & $<0.001$ \\
\hline Vasopressor in first 48 h (\%) & 0.80 & 6.67 & 7.69 & 0.030 \\
\hline Artificial colloid (\%) & 38.46 & 53.72 & 53.85 & 0.341 \\
\hline Albumin (\%) & 57.69 & 34.71 & 32.05 & 0.540 \\
\hline Urine output at shock stage $\left(\%, \geq 0.5 \mathrm{ml} / \mathrm{kg} \cdot \mathrm{h}^{-1}\right)$ & 97.60 & 75.00 & 64.84 & $<0.001$ \\
\hline Nephrotoxic drugs (\%) & 23.08 & 51.24 & 55.13 & 0.015 \\
\hline Length of mechanical ventilation (days) & $0(0.00)$ & $0(2.00)$ & $1(6.00)$ & $>0.001$ \\
\hline Sepsis during ICU stay (\%) & 15.20 & 46.11 & 67.03 & $<0.001$ \\
\hline Positive blood culture (\%) & 54.51 & 58.37 & 87.12 & $<0.001$ \\
\hline Gram-positive bacteria (\%) & 9.68 & 51.61 & 38.71 & $<0.001$ \\
\hline Gram-negative bacteria (\%) & 23.53 & 50.00 & 26.47 & $<0.001$ \\
\hline Positive culture, others (\%) & 0.00 & 51.56 & 48.44 & $<0.001$ \\
\hline Maximum RIFLE & & & & $<0.001$ \\
\hline No AKI $(\%, n=245)$ & 51.02 & 36.73 & 12.24 & $<0.001$ \\
\hline Risk $(\%, n=83)$ & 0.00 & 61.45 & 38.55 & $<0.001$ \\
\hline Injury $(\%, n=52)$ & 0.00 & 61.54 & 38.46 & $<0.001$ \\
\hline Failure $(\%, n=16)$ & 0.00 & 43.75 & 56.25 & $<0.001$ \\
\hline Maximum SOFA & $0(0.00)$ & $4(7.00)$ & $6(8.00)$ & $<0.001$ \\
\hline CRRT during ICU stay (\%) & 0.00 & 5.00 & 7.69 & $<0.001$ \\
\hline Length of CRRT treatment (days) & $0(0.00)$ & $0(0.00)$ & $0(2.00)$ & 0.013 \\
\hline ICU length of stay (days) & $0(0.00)$ & $2(30.00)$ & $4(49.00)$ & $<0.001$ \\
\hline ICU mortality (\%) & 0.8 & 16.67 & 30.77 & $<0.001$ \\
\hline
\end{tabular}

ACS, abdominal compartment syndrome; CRRT, continuous renal replacement therapy; dTBSA, total surface area of deep second degree or third degree burn; ICU, intensive care unit; RIFLE, Risk, Injury, Failure, Loss, End Stage classification; SOFA, sequential organ failure assessment; TBSA, total burn surface area. Continuous variables, median (quartile range); categorical variables, (\%).

Variables coding: Maximum RIFLE 1: No-AKI, 2: Risk, 3: Injury, 4: Failure + loss + end stage

burn patients. Furthermore, some patients with proteinuria may die before they are diagnosed with AKI.

It is established that the risks of death and AKI progression, or end-stage renal disease associated with AKI, vary with levels of proteinuria [10,35]. Proteinuria in the absence of AKI is common in severe burn patients and may indicate sub-clinical AKI. However, current guidelines for the classification and staging of AKI do not explicitly consider concomitant proteinuria [13] and, therefore, may not identify individuals at risk for developing AKI when $\mathrm{sCr}$ is normal but proteinuria exists.

Dipstick urinalysis was used for measurement of proteinuria in our study. Dipstick urinalysis has less favorable diagnostic properties for the assessment of proteinuria than quantitative measurements of proteinuria, such as 24-hour urine collection tests. However, it is the most common test and is much cheaper, readily available, feasible and practical, compared with automated measures. The validity of proteinuria readings was established with a significant correlation between dipstick and 24-hour urine collection testing using bivariate correlation analysis $(n=$ $40, P<0.001$; data not shown). Although our findings do not address whether dipstick urinalysis or urine sample measurement of albumin is preferable for risk assessment in clinical practice, they do suggest that for burn patients, testing of proteinuria using simple dipstick methodology is prognostic for AKI outcomes.

The majority of proteinuria in AKI is due to tubular injury that prevents protein absorption, as well as release of tubular proteins into the ultrafiltrate. However, kidney 
Table 3 Characteristics and outcomes of patients with proteinuria according to AKI $(n=271)$

\begin{tabular}{|c|c|c|c|}
\hline & $\begin{array}{l}\text { Proteinuria without AKI } \\
(n=120)\end{array}$ & $\begin{array}{l}\text { Proteinuria accompanied with AKI } \\
(n=151)\end{array}$ & $P$-value \\
\hline Age (years) & $41(17.75)$ & $41(16.00)$ & 0.685 \\
\hline Gender ( $\%$ of male) & 72.80 & 79.17 & 0.200 \\
\hline TBSA (\%) & $47.5(34.75)$ & $70(35.00)$ & $<0.001$ \\
\hline dTBSA (\%) & $42(25.75)$ & $58(37.00)$ & $<0.001$ \\
\hline Escharotomy (\%) & $7(28.50)$ & $18(38.00)$ & $<0.001$ \\
\hline Electrical injury (\%) & 8.33 & 8.61 & 0.936 \\
\hline Chemical injury (\%) & 19.17 & 12.58 & 0.138 \\
\hline Inhalation injury (\%) & 43.33 & 50.33 & 0.226 \\
\hline Comorbidities (\%) & 10.00 & 8.95 & 0.630 \\
\hline ACS (\%) & 14.17 & 25.17 & 0.033 \\
\hline Vasopressor in first $48 \mathrm{~h}(\%)$ & 5.00 & 8.61 & 0.249 \\
\hline Artificial colloid (\%) & 56.14 & 52.82 & 0.672 \\
\hline Albumin (\%) & 42.11 & 30.28 & 0.111 \\
\hline Proteinuria at heavy stage (\%) & 22.71 & 42.14 & 0.001 \\
\hline Urine output in shock stage $\left(\%, \geq 0.5 \mathrm{ml} / \mathrm{Kg} \cdot \mathrm{h}^{-1}\right)$ & 77.19 & 54.93 & $<0.001$ \\
\hline Nephrotoxic drugs (\%) & 45.61 & 55.63 & 0.202 \\
\hline Length of mechanical ventilation (days) & $0(3.00)$ & $1(6.00)$ & $<0.001$ \\
\hline Sepsis during ICU stay (\%) & 41.67 & 62.25 & 0.001 \\
\hline Positive blood culture (\%) & 71.28 & 74.35 & 0.102 \\
\hline Maximum SOFA & $0(5.00)$ & $7(9.00)$ & $<0.001$ \\
\hline CRRT during ICU stay (\%) & 8.30 & 9.93 & 0.002 \\
\hline Length of CRRT treatment (days) & $0(0.00)$ & $0(2.00)$ & 0.002 \\
\hline ICU length of stay (days) & $0(24.75)$ & $11(45.00)$ & $<0.001$ \\
\hline ICU mortality (\%) & 12.50 & 28.48 & 0.001 \\
\hline
\end{tabular}

ACS, abdominal compartment syndrome; AKI, acute kidney injury; CRRT, continuous renal replacement therapy; ICU, intense care unit; SOFA, sequential organ failure assessment; TBSA, total burn surface area; tTBSA, total surface area of third degree burn. Continuous variables, median (quartile range); categorical variables, (\%)

biopsies of eight patients with persistent $\mathrm{AKI} /$ proteinuria documented co-existent glomerular disease (data not shown). This suggests that the role of glomerular injury in AKI, particularly where there is sepsis and inflammation, is incompletely understood and may be of greater significance than currently recognized.

Intrinsic AKI is often multifactorial. Renal ischemia is probably less important in the acute phase of burn injury than originally presumed [36]. Instead, inflammation and sepsis probably play important roles [37-39]. An important difference between burn and other types of ICU patients may be the intensity and duration of the inflammatory response, which may persist longer than in other trauma patients [40]. Sepsis in severe burn patients, often accompanied by multi-organ failure (represented by SOFA), was identified as a risk factor for proteinuria by our regression analysis (Table 4), as well as for AKI (Table 5). Sepsis-related inflammatory and thrombogenic factors are considered risk factors for direct renal parenchymal damage $[41,42]$.

This observational study has limitations. First, the burn patients were primarily male, and misclassifications of baseline kidney function could have occurred because of deficiencies in previous examinations. Second, misclassifications of proteinuria might occur because of known variability of urine dipstick measurements, even though

Table 4 Logistic regression model: risk factors for proteinuria $(n=396)$

\begin{tabular}{llll}
\hline Covariates associated with proteinuria & Coefficient & Odds ratio & 95\% Confidence interval \\
\hline TBSA (\%) & 0.037 & 1.038 & 1.022 to 1.054 \\
Sepsis during ICU stay & 1.052 & 2.864 & 1.539 to 5.331 \\
Age & 0.026 & 1.026 & 1.007 to 1.046 \\
\hline
\end{tabular}

ICU, intense care unit; TBSA, total burn surface area

Covariates selected: Age, TBSA, ACS, inhalation injury, vasopressor in the first $48 \mathrm{~h}$, comorbidities, albumin, sepsis during ICU stay

Variables coding: Proteinuria 1: $(-), 2: \geq( \pm)$ 
Table 5 Logistic regression model: risk factors for AKI $(n=396)$

\begin{tabular}{lllll}
\hline Covariates associated with AKI & Coefficient & Odds ratio & 95\% Confidence interval & $P$-value \\
\hline Maximum SOFA & 0.324 & 1.383 & 1.267 to 1.509 & $<0.001$ \\
Proteinuria & 1.500 & 4.480 & 2.824 to 7.108 & $<0.001$ \\
\hline
\end{tabular}

SOFA, sequential organ failure assessment

Covariates selected: Age, TBSA, ACS, inhalation injury, vasopressor in the first $48 \mathrm{~h}$, comorbidities, sepsis during ICU stay, maximum SOFA, proteinuria Variables coding: AKI 1: No occurrence of RIFLE criteria, 2: Occurrence of RIFLE criteria; Proteinuria 1: $(-), 2:( \pm)$ or $(+), 3: \geq(++)$

Table 6 Logistic regression model: risk factors for ICU mortality $(n=396)$

\begin{tabular}{lllll}
\hline Covariates associated with ICU mortality & Coefficient & Odds ratio & 95\% Confidence interval & $P$-value \\
\hline Proteinuria & 0.659 & 1.932 & 1.000 to 3.734 & 0.050 \\
Maximum RIFLE & 0.828 & 2.289 & 1.577 to 3.322 & $<0.001$ \\
Comorbidities & 2.446 & 11.545 & 3.986 to 33.440 & $<0.001$ \\
Age & 0.065 & 1.068 & 1.029 to 1.108 & $<0.001$ \\
TBSA & 0.462 & 1.587 & 1.421 to 1.772 & $<0.001$ \\
\hline
\end{tabular}

RIFLE, Risk, Injury, Failure, Loss, End Stage classification;

SOFA, sequential organ failure assessment; TBSA, total burn surface area. Covariates selection: Age, TBSA, ACS, inhalation injury, vasopressor in the first 48 h, comorbidities, sepsis during ICU stay, proteinuria, maximum RIFLE

Variables coding: Proteinuria 1: (-), 2: $( \pm)$ or $(+), 3: \geq(++)$; Maximum RIFLE: 1: No-AKI, 2: Risk, 3: Injury, 4: Failure + loss + end stage

There was no interaction between proteinuria and RIFLE.

we established a significant correlation between dipstick measurements and the $24 \mathrm{~h}$ urine test. Finally, we could not exclude the possibility of residual confounding due to burn severity, blood pressure, large amounts of fluid resuscitation and the administration of drugs. Furthermore, the unusual composition of urinary proteins (decreased filtered load of albumin, increased load of acute phase reactants or alterations in protein processing in renal tubules) compromises the use of urinary protein measurements for detecting kidney injury in burn patients [27]. Nonetheless, our results were consistent for several clinically relevant outcomes, including AKI, CRRT and mechanical ventilation duration, ICU length of stay and mortality. These findings are important because current guidelines for the classification and staging of $\mathrm{AKI}$ are based on $\mathrm{sCr}$ and urine volume, without explicit consideration of the severity of concomitant or independently existing proteinuria, especially in severe burn patients.

\section{Conclusions}

In conclusion, proteinuria was common $(68.26 \%)$ in severe burn patients ( $>30 \%$ TBSA), and proteinuria was clearly associated with increased risk for developing AKI, long-term ICU stays and mortality. Age, TBSA and sepsis were considered as independent risk factors for proteinuria in the post-burn period, and maximum SOFA and proteinuria as risk factors for AKI. Age, TBSA, proteinuria, comorbidities and RIFLE were regarded as risk factors for ICU mortality. These findings demonstrate that proteinuria should be used to identify severe burn patients at risk of developing AKI and unfavorable clinical outcomes.

\section{Key messages}

- Almost two-thirds of severe burn patients (> 30\% TBSA) develop new onset proteinuria.

- Proteinuria is associated with increased risk for AKI, ICU length of stay and mortality.

- Age, TBSA and sepsis are considered as independent risk factors for proteinuria in the post-burn period.

- Maximum SOFA and proteinuria are regarded as risk factors for AKI.

\section{Additional material}

Additional file 1: The Third Military Medical University formula. A description of the Third Military Medical University formula for patient resuscitation.

\section{Abbreviations}

ACS: abdominal compartment syndrome; AKl: acute kidney injury; CKD: chronic kidney disease; CRRT: continuous renal replacement therapy; GFR: glomerular filtration rate; IAP: intra-abdominal pressure; ICU: intense care unit; MDRD: Modification of Diet in Renal Disease; MODS: multiple organ dysfunction syndrome; RIFLE classification: Risk, Injury, Failure, Loss, End Stage classification; sCr: serum creatinine; SIRS: systemic inflammatory response syndrome; SOFA: sequential organ failure assessment; TBSA: total burn surface area.

\section{Authors' contributions}

HJY participated in conception, design, data analysis and manuscript drafting. MXC and LQZ participated in conception, design, data acquisition and interpretation, and critical revision of the manuscript. HJ was involved in data analysis and drafting the manuscript. HYS was involved in revising the manuscript for important intellectual content, and supervision. PYZ and WJ participated in the study design and critically revised the manuscript for important content. XF and FYD participated in collecting data and coordination. WYZ participated in statistical analysis and revision of the manuscript for important intellectual content. All authors read and approved the final manuscript. 


\section{Competing interests}

The authors declare that they have no competing interests.

\section{Acknowledgements}

This study was supported by the National Key Technology Research and Development Program of the Ministry of Science and Technology of China (2009BAl87B03) and the Medical Project of Ministry of Health of China (201202002)

\section{Author details}

'Institute of Burn Research, Southwest Hospital, State Key Laboratory of Trauma, Burns and Combined Injury, Chongqing Key Lab for Disease Proteomics, Third Military Medical University, Chongqing 400038, PR China. ${ }^{2}$ Burn Department, People Hospital of Changshou District, Chongqing 401220, PR China. ${ }^{3}$ Department of Gynecology and Obstetrics, Daping Hospital, Third Military Medical University, Chongqing 400042, PR China. ${ }^{4}$ Department of Statistics, Third Military Medical University, Chongqing 40038, PR China.

Received: 9 April 2012 Revised: 7 June 2012

Accepted: 29 September 2012 Published: 29 September 2012

\section{References}

1. Chertow GM, Burdick E, Honour M, Bonventre JV, Bates DW: Acute kidney injury, mortality, length of stay, and costs in hospitalized patients. J Am Soc Nephrol 2005, 16:3365-3370.

2. Lopes JA, Jorge S, Neves FC, Caneira M, da Costa AG, Ferreira AC, Prata MM: An assessment of the RIFLE criteria for acute renal failure in severely burned patients. Nephrol Dial Transpl 2007, 22:285.

3. Kim GH, Oh KH, Yoon JW, Koo JW, Kim HJ, Chae DW, Noh JW, Kim JH, Park YK: Impact of burn size and initial serum albumin level on acute renal failure occurring in major burn. Am J Nephrol 2003, 23:55-60.

4. Curiel-Balsera E, Prieto-Palomino MA, Fernandez-Jimenez S, FernandezOrtega JF, Mora-Ordonez J, Delgado-Amaya M: Epidemiology, initial management and analysis of morbidity-mortality of severe burn patient. Med Intensiva 2006, 30:363-369.

5. Palmieri T, Lavrentieva A, Greenhalgh DG: Acute kidney injury in critically ill burn patients. Risk factors, progression and impact on mortality. Burns 2010, 36:205-211.

6. Coca SG, Yusuf B, Shlipak MG, Garg AX, Parikh CR: Long-term risk of mortality and other adverse outcomes after acute kidney injury: a systematic review and meta-analysis. Am J Kidney Dis 2009, 53:961-973.

7. Leblanc M, Thibeault Y, Querin S: Continuous haemofiltration and haemodiafiltration for acute renal failure in severely burned patients. Burns 1997, 23:160-165.

8. Sun IF, Lee SS, Lin SD, Lai CS: Continuous arteriovenous hemodialysis and continuous venovenous hemofiltration in burn patients with acute renal failure. Kaohsiung J Med Sci 2007, 23:344-351.

9. Tremblay R, Ethier J, Querin S, Beroniade V, Falardeau P, Leblanc M: Venovenous continuous renal replacement therapy for burned patients with acute renal failure. Burns 2000, 26:638-643.

10. Steinvall I, Bak Z, Sjoberg F: Acute kidney injury is common, parallels organ dysfunction or failure, and carries appreciable mortality in patients with major burns: a prospective exploratory cohort study. Crit Care 2008, 12:R124.

11. Abdel-Rahman E, Moorthy V, Helgerson RB, Omari B: Acute renal failure (ARF) requiring dialysis in patients with burns: 16 years experience in one center. Clin Nephrol 1997, 8:A576-A0576.

12. Bellomo R, Ronco C, Kellum JA, Mehta RL, Palevsky P, ADQI workgroup: Acute renal failure - definition, outcome measures, animal models, fluid therapy and information technology needs: the Second International Consensus Conference of the Acute Dialysis Quality Initiative (ADQI) Group. Crit Care 2004, 8:204-212.

13. Mehta RL, Kellum JA, Shah SV, Molitoris BA, Ronco C, Warnock DG, Levin A: Acute Kidney Injury Network: Acute Kidney Injury Network: report of an initiative to improve outcomes in acute kidney injury. Crit Care 2007, 11:R31.

14. Star RA: Treatment of acute renal failure. Kidney Int 1998, 54:1817-1831.

15. Hsu CY, Ordonez JD, Chertow GM, Fan D, McCulloch CE, Go AS: The risk of acute renal failure in patients with chronic kidney disease. Kidney Int 2008, 74:101-107.
16. James MT, Hemmelgarn BR, Wiebe N, Pannu N, Manns BJ, Klarenbach SW, Tonelli M: Glomerular filtration rate, proteinuria, and the incidence and consequences of acute kidney injury: a cohort study. Lancet 2010, 376:2096-2103.

17. Grams M, Coresh J: Proteinuria and risk of acute kidney injury. Lancet 2010, 376:2046-2048.

18. Thomas AA, Demirjian S, Lane BR, Simmons MN, Goldfarb DA, Subramanian VS, Campbell SC: Acute kidney injury: novel biomarkers and potential utility for patient care in urology. Urology 2011, 77:5-11.

19. Soni SS, Pophale R, Ronco C: New biomarkers for acute renal injury. Clin Chem Lab Med 2011, 49:1257-1263.

20. Moore E, Bellomo R, Nichol A: Biomarkers of acute kidney injury in anesthesia, intensive care and major surgery: from the bench to clinical research to clinical practice. Minerva Anestesiol 2010, 76:425-440.

21. Viberti GC, Hill RD, Jarret RJ, Argyropoulos A, Mahmud U, Keen H: Microalbuminuria as a predictor of clinical nephropathy in insulindependent diabetes mellitus. Lancet 1982, 1:1430-1432.

22. Arnlöv J, Evans JC, Meigs JB, Wang TJ, Fox CS, Levy D, Benjamin EJ, D'Agostino RB, Vasan RS: Low-grade albuminuria and incidence of cardiovascular disease events in nonhypertensive and nondiabetic individuals: the Framingham Heart Study. Circulation 2005, 112:969-975.

23. Abid O, Sun $Q$, Sugimoto K, Mercan D, Vincent JL: Predictive value of microalbuminuria in medical ICU patients: results of a pilot study. Chest 2001, 120:1984-1988.

24. Sarti A, Raffaele-De GA, Messineo A, Cuttini M, Ventura A: Glomerular permeability after surgical trauma in children: relationship between microalbuminuria and surgical stress score. Crit Care Med 2001, 29:1626-1629.

25. MacKinnon K, Lowe ZMD, Watson I, Shearer E: Use of microalbuminuria as a predictor of outcome in critically ill patients. Brit J Anaesth 2000, 84:239-241.

26. Gosling P, Brudney S, McGrath LS, Riseboro S, Manji M: Mortality prediction at admission to intensive care: a comparison of microalbuminuria with acute physiology scores after 24 hours. Crit Care Med 2003, 31:98-103.

27. Sviridov D, Owen WE, Roberts WL, Edelman LS, Drake SK, Hortin GL: Proteinuria without albuminuria: urinary protein excretion by a subset of patients with burn injuries. Clin Chim Acta 2009, 403:42-46.

28. Gosling P, Sutcliffe AJ, Cooper MA, Jones AF: Burn and trauma associated proteinuria: the role of lipid peroxidation, renin and myoglobin. Ann Clin Biochem 1988, 25:53-59.

29. Luo GX, Peng YZ, Zhuang Y, Zhang LH, Zhou M, Cheng WG, Wu J, Zhang JP, Yuan ZQ, Luo QZ, Huang YS: Clinical practice and evaluation of relative fluid resuscitation formula at burn shock stage. Chinese J Burns 2008, 24:248-250.

30. Malbrain ML, Cheatham ML, Kirkpatrick A, Sugrue M, Parr M, De Waele J, Balogh Z, Leppaniemi A, Olvera C, Ivatury R, D'Amours S, Wendon J, Hillman K, Johansson K, Kolkman K, Wilmer A: Results from the International Conference of Experts on Intra-abdominal Hypertension and Abdominal Compartment Syndrome. I. Definitions. Intens Care Med 2006, 32:1722-1732.

31. Tina P, Athina L, David GG: Acute kidney injury in critically ill burn patients. Risk factors, progression and impact on mortality. Burns 2010, 36:205-211.

32. American College of Chest Physicians/Society of Critical Care Medicine Consensus Conference: definitions for sepsis and organ failure and guidelines for the use of innovative therapies in sepsis. Crit Care Med 1992, 20:864-874.

33. Vincent JL, Moreno R, Takala J, Willatts S, De Mendonça A, Bruining H, Reinhart CK, Suter PM, Thiij LG: The SOFA (Sepsis-related organ failure assessment) score to describe organ dysfunction/failure. On behalf of the working group on sepsis-related problems of the European society of intensive care medicine. Intens Care Med 1996, 22:707-710.

34. Hilton R: Acute renal failure. Brit Med J 2006, 333:786-790.

35. Bouchard J, Macedo E, Soroko S, Chertow GM, Himmelfarb J, Ikizler TA, Paganini EP, Ravindra L: Comparison of methods for estimating glomerular filtration rate in critically ill patients with acute kidney injury. Nephrol Dial Transpl 2010, 25:102-107.

36. Langenberg C, Wan L, Egi M, May CN, Bellomo R: Renal blood flow in experimental septic acute renal failure. Kidney Int 2006, 69:1996-2002.

37. Mehta RL, Pascual MT, Soroko S, Savage BR, Himmelfarb J, Ikizler TA, Paganini EP, Chertow GM: Spectrum of acute renal failure in the intensive care unit: the PICARD experience. Kidney Int 2004, 66:1613-1621. 
38. Colpaert K, Hoste EA: Acute kidney injury in burns: a story of volume and inflammation. Crit Care 2008, 12:R192.

39. Wan L, Bellomo R, Di Giantomasso D, Ronco C: The pathogenesis of septic acute renal failure. Curr Opin Crit Care 2003, 9:496-502.

40. Jeschke MG, Mlcak RP, Finnerty CC, Norbury WB, Gauglitz GG, Kulp GA, Herndon DN: Burn size determines the inflammatory and hypermetabolic response. Crit Care 2007, 11:R90.

41. Paisley KE, Beaman M, Tooke JE, Mohamed-Ali V, Lowe GD, Shore AC: Endothelial dysfunction and inflammation in asymptomatic proteinuria. Kidney Int 2003, 63:624-633.

42. Stehouwer CD, Gall MA, Twisk JW, Knudsen E, Emeis JJ, Parving HH: Increased urinary albumin excretion, endothelial dysfunction, and chronic low-grade inflammation in type 2 diabetes: progressive, interrelated, and independently associated with risk of death. Diabetes 2002, 51:1157-1165.

doi:10.1186/cc11649

Cite this article as: Hu et al:: Relation between proteinuria and acute kidney injury in patients with severe burns. Critical Care 2012 16:R172.

\section{Submit your next manuscript to BioMed Central} and take full advantage of:

- Convenient online submission

- Thorough peer review

- No space constraints or color figure charges

- Immediate publication on acceptance

- Inclusion in PubMed, CAS, Scopus and Google Scholar

- Research which is freely available for redistribution

Submit your manuscript at www.biomedcentral.com/submit 